\title{
Are People Controlling the Danger or Fear for Condom Use as HIV/AIDS Preventive Message? An Evaluative Type of Study Based on Extended Parallel Process Model
}

\section{Feleke Doyore', Zewdie Birhanu², Yohannes Kebede ${ }^{2}$, Tariku Dejene ${ }^{2}$ and Dube Jara ${ }^{3 *}$}

${ }^{1}$ Wachemo University, College of Medicine and Health Science, Department of Public Health, P.O. Box: 667 Wachemo, Ethiopia

${ }^{2}$ Jimma University, College of Public Health and Medical Science, Department of Health Eduaction and behavioral science, P.O. Box: 378 Jimma, Ethiopia

${ }^{3}$ Debre Markos University, College of Medicine and Health Science, Department of Public Health, P.O. Box: 269 Debre Markos, Ethiopia

\section{Abstract}

Background: There almost three decade years after the first clinical cases of AIDS were reported; it has become the most devastating disease of world particplarly in developing world. Despite massive resources and intensified interventions were made in promoting condom use as prevention methods, desired decline has not been achieved. This study was aimed to evaluate how people controlling the Danger or Fear for condom use as HIVIAIDS preventive message among youths exposed to messages and the response they experience on messages.

Methods: Cross-sectional study design was conducted using quantitative and qualitative methods of data collection. Pre-tested self administered questionnaires were used to collect data. Study participants were selected using stratified random sampling from hosanna public college students. Quantitative data were analyzed using SPSS version 16.0. Thematic analysis was use for qualitative data.

Results: Hundred ninty one (48.1\%) of the respodents were found in danger control responses, whereas 206 $(51.9 \%)$ were found in fear control responses. Perceived susceptibility to and severity of HIVIAIDS was relatively high; however, perceived self efficacy and response efficacy to HIV prevention messages had lower scores. Perceived susceptibility $[\beta(95 \% \mathrm{Cl})=1.07(1.21$ to 7.10$)]$ and severity of $[\beta(95 \% \mathrm{Cl}=1.65(1.25$ to 21.81$)]$ HIV/AIDS were positively associated factors for fear control responses. Self efficacy $[\beta(95 \% \mathrm{Cl})=-0.96(0.16$ to 0.92$)]$ and response efficacy $[\beta$ $(95 \% \mathrm{Cl})=-1.21(0.11$ to 0.83$)]$ were negatively associated factors. Totally, $66.3 \%$ of the variance in the response of condom use message as HIV prevention could be explained by EPPM model.

Conclusion: Despite higher numbers of students were in fear control psychological responses, there were gaps between discriminative scores and most of the current behavior. Perceived susceptiblity, severity, self efficacy and response efficacy were independent predictors of students' perceptions to use recommended responses. Due attention should given to fill the gap of perception of both susceptibility and severity.

Keywords: Critical values; Perceived threat; Efficacy; Danger or fear control

\section{Introduction}

No other disease in recent history has generated so much concern, fear, anxiety, and prejudice both among health care personnel and the general public as has HIV/AIDS; even if the global response to the HIV/AIDS pandemic began more than a decade ago, however the required achievement in decreasing the prevalence of the disease does not occur [1].

Still global burden of HIV/AIDS remain enormous. Infact the present worldwide HIV pandemic consists of many regional epidemics; Sub-Saharan Africa remains the worst affected region by the pandemic being home to two-thirds (67\%) of the global total of 34 million people living with HIV. As a report of UNAIDS 2011, globally, 2.7 million were new infections and 2 million were AIDS-related deaths. Of this figure, in Sub-Saharan Africa, 1.9 million (70.4\%) were new infections and 1.4 million (70\%) were AIDS-related deaths. According to UNAIDS 2011, $\mathrm{HIV}$ and AIDS prevalence in Young people covering the age range 1024 years is high, which account for $45 \%$ of all new HIV infections in adults making them to be called the "risky population." [1,2].

The overall HIV prevalence estimate for Ethiopia in 2011 was $2.3 \%$ and is in increasing in trend [1,2]. Also, the adult HIV prevalence in urban areas is much higher (7.7\%) than in rural areas (0.9\%) [3]. Following that the disease (AIDS) became a major public health problem in nowadays [1].
Unprotected sex is the main causes for HIV infection in SubSaharan Africa including Ethiopia in every age group. The associated behavioral factors stated are multiple sexual partners and not using the recommended responses such as condoms and environmental factors like peer pressure, increasing urbanization and the cultural factors like fear to buy condoms, which in turn leads nowadays the young people to be called as "AIDS generation" $[1,4,5]$. Considering the above ravaging effects of HIV/AIDS pandemic, globally with the urgent impulse to "do something and anything", launched HIV prevention programs pursuing such goals as reaching people with information and distribution of condoms, and with little attention paid to the ultimate effectiveness beyond communication and education [5].

${ }^{*}$ Corresponding author: Dube Jara, Debre Markos University, College of Medicine and Health Science, Department of Public Health, P.O. Box: 269 Debre Markos, Ethiopia, Tel: +251 0913910575; 0920769736; E-mail: jaradube@yahoo.com; duhoney05@gmail.com

Received October 24, 2013; Accepted November 25, 2013; Published November 30,2013

Citation: Doyore F, Birhanu Z, Kebede Y, Dejene T, Jara D (2013) Are People Controlling the Danger or Fear for Condom Use as HIVIAIDS Preventive Message? An Evaluative Type of Study Based on Extended Parallel Process Model. J AIDS Clin Res 4: 264. doi:10.4172/2155-6113.1000264

Copyright: (C) 2013 Doyore F, et al. This is an open-access article distributed under the terms of the Creative Commons Attribution License, which permits unrestricted use, distribution, and reproduction in any medium, provided the original author and source are credited. 


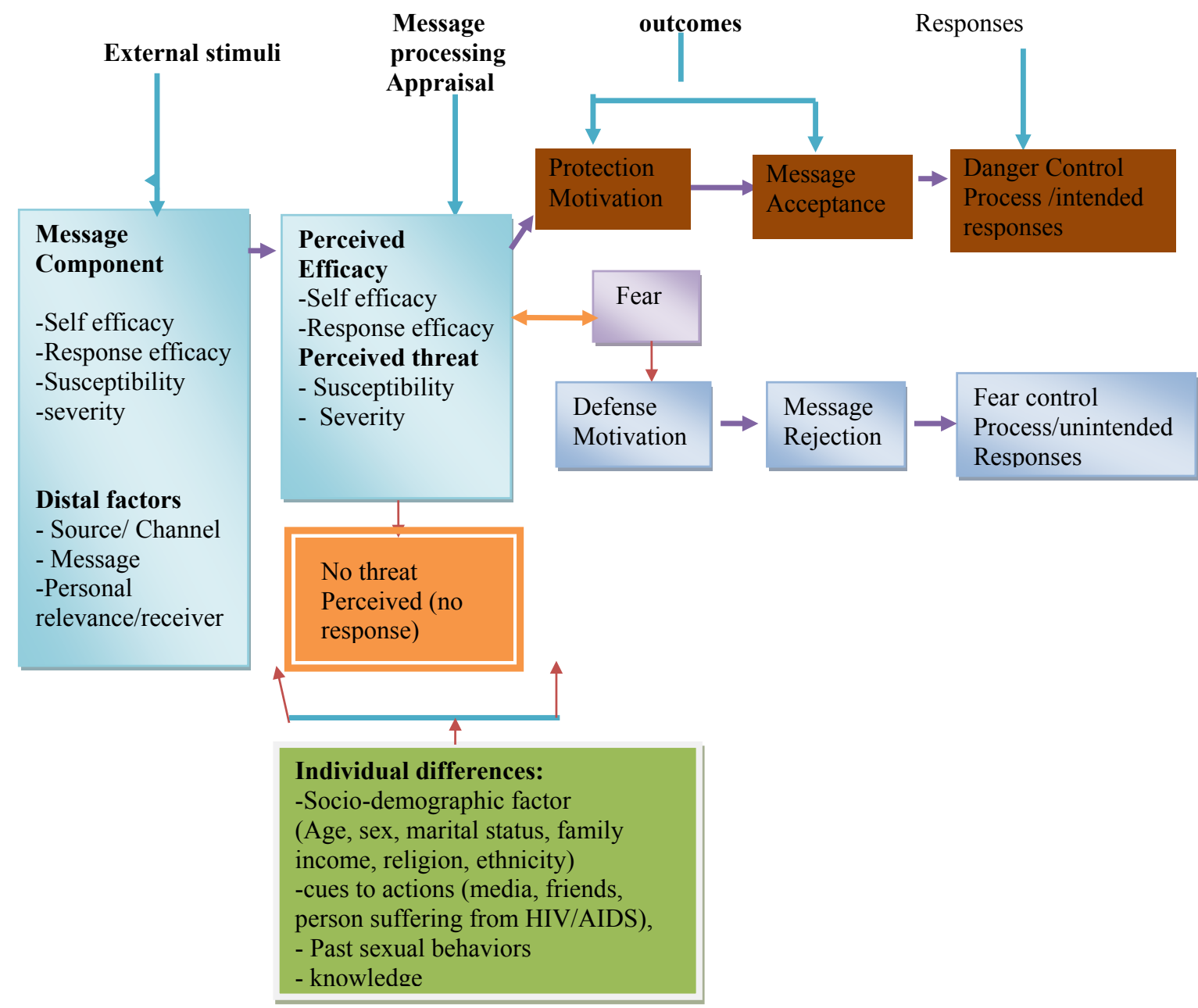

Figure 1: Conceptual Framework of the Model in this Research [19].

Despite the advance over two decades of communication efforts (by lounching IEC/BCC strategies), however, HIV rates have continued to rise globally, especially the young people aged 15-24 accounts for more than 50 percent of the entire worldwide infection [6].

In 2008 the Ethiopia National Demographic and Health Survey (NDHS) showed wide gaps between awareness and correct knowledge of HIV transmission and the appropriate methods of prevention [7]. Insufficiency of increasing awareness thereafter the emphasis in HIV/ AIDS communication efforts, globally, is increasingly shifting from IEC to behavior change communication (BCC), which has been described as a second-generation HIV communication intervention. This general development in the health communication field, noted to be the "era of strategic behavior change communication, founded on behavioral science models" [8].

Theories and models help to explain the process that individuals go through changes as they exchange information and to react to different messages. In this study, Extended Parallel Process Model (EPPM) attempts to explain when and why the recommended message work or fail. Since the EPPM restores the concept of fear as a central variable in investigating fear appeal. According to the initial tenets of the EPPM, when an individual is exposed to a fear appeal, two cognitive appraisals of the message will occur: first, the "appraisal of the threat" and second, the "appraisal of the efficacy" of the message's recommended response, or as Perloff suggested, as a problem (threat) and solution (efficacy information). EPPM assumes that if the perceived threat is perceived to be high (for instance, "AIDS takes life") and the level of efficacy appraised, individuals will be appraised to follow one of two separate pathways: the danger control process and fear control process $[9,10]$.

The model, primarily, is designed for campaign message evaluation to see category of individual whether they are using the recommended response or not by Witte [10] which really parallels with this research which is aimed to assess response to HIV preventive messages that can show the category of students. Therefore, this study is important to give attention to assess the in school youths exposure to messages and the response they experience on messages using EPPM. Furthermore, the findings of this study will enable colleges, message developers, health educators, HAPCO, researchers and policy makers used as baseline data to design appropriate and effective messages (Figure 1).

\section{Methods and Materials}

\section{Study setting and period}

This study was conducted in Hosanna town among the three 
public colleges of Hosanna town: namely Health Science College, Poly Technic College and Teachers Training College for over a period of tweleve days (as of January 28 to February 10/2012). In 2012, a total of 7211 students were enrolled in all programs in the three colleges from different areas of the zones of the region for a maximum of three years training residing outside of the college compound.

\section{Study design and populations}

Institutional based Cross-sectional study design was conducted using both quantitative and qualitative data collection methods on students of Hosanna Colleges, Hadiya zone, South Ethiopia. Source populations were all students on three Hossana colleges. All sampled regular students of three Hosanna colleges who were present during study period were included.

\section{Sample size and sampling procedure}

The required Sample size was determined using single population formula by considering $50 \%$ estimated proportion of danger control respose because there is no study conducted in related topic in the study area to the understanding of investigators, margin of error $5 \%$, a $5 \%$ level of significance (two sided) i.e. 95\% confidence interval of certainty. Based on the above assumptions, with an additional 10 percent contingency for non-response the total sample size was 421 . Nine in-depth interviews were conducted with teachers and four focus group discussions were conducted students club member. Stratified random sampling technique was used to select study participants from student roster of each college through proportional to size (PS) allocation technique. Purposive sampling was used for the in-depth interview and FGD.

\section{Measurement and variables}

Socio-demographics characteristics: such as age, sex, marital status, religion, residence, income and so on. Knowledge - Knoweldge about HIV/AIDS was assessed using 17 items with response format of 'yes' or 'no'. Respondants were asked not to guess, but to mark the "I don'tknow" answer possibility if they did not know the correct answer. Knowledgeable - those respondents who answered seventy percent and above of all the knowledge questions about HIV/AIDS. Not Knowledgeable - those respondents who answered below seventy percent of all the knowledge questions about HIV/AIDS.

Perceived susceptibility: HIV/AIDS is respondent's self perception of vulnerability to HIV/AIDS and it was measured by five point Likert scale items. Similary, perceived severity of HIV/AIDS is respondent's belief concerning the effects of a given disease seriousness or condition would have on one's state of health affairs and it also measured on 5-point Likert scale. Perceived efficacy is respondent's perception of one's harm/threat from HIV/AIDS can be prevented by their ability and belief of effectiveness of the response (i.e. the sum of Perceived selfefficacy and response efficacy). Twenty six items were used to assess perceived efficacy on five point likert scale ranging from complete disagreement ' $=1$, 'somewhat diagree' $=2$, 'neither disagreement nor agreement' $=3$, 'somewhat agree' $=4$ and 'to complete agreement $=5$. Not applicable option was included. After reversing for negatively worded items, scores were summed for each respective concept.

Danger control responses: When people believe they are at-risk for health threat that is HIV (i.e., high perceived threat), and they believe they are able to effectively avert it from occurring (i.e., high perceived efficacy), they are motivated to control the danger or threat.

Fear control responses: When students believe they are at-risk for a serious or significant threat (HIV/AIDS) (i.e., high perceived threat), but they believe they are unable to perform the recommended response or they believe the recommended response to be ineffective (i.e., low perceived efficacy), then they focus on controlling their fear about the threat. No responses/No threat-respondents' with low threat perceptions regarding a health threat are neither engaging in danger nor fear control i.e. weighted efficacy score minus weighted threat score is neither negative nor positive. To determine critical value/ discriminative score, the sum of threat score was substructed from sum of efficacy score. Negative Scores-Perception scores that indicate people are controlling their fear (and not the danger) about HIV/AIDS. Positive Scores-Perception scores that indicate people are controlling their danger (and not the fear) about HIV/AIDS. On the other hand, when the critical value is zero, it is considered as No responses $[11,12]$.

\section{Data collection instrument and procedure}

Quantitative data were collected using structured self administered questionnaires through guidance of experienced data collector. The questionnaire was adapted from literature in English to increase the comparability of the finding. Qualitative data were collected by principal investigators using FGD and IDI from students' club member. The guideline which inquiries about the reason why they are responding or not, respondents logical decisions in accepting or not accepting the message, perceived difference of acceptors and rejecters, and preferred sources, message type, delivering style with some probing questions were prepared for students and teachers separately. Respective responses of informants were recorded by using tape recorder and hand written notes, and were analyzed by using Atlas software.

\section{Data quality management, processing and analysis}

Questionnaires were translated to Amharic and then back translated to English to maintain its consistency. Training was given for data collectors and pretest was made on $5 \%$ of the participants in a Durame Poly Technic College which was similar population before the actual data collection. Supervisors and principal investigator performed immediate supervision on a daily basis. Each and every completed questionnaire was checked for completeness. In qualitative study, the recorded voice was transcribed first in Amharic and translated to English to keep consistency of the original meaning. The collected data were entered in EPI data version 3.1 computer programs. Prior to the analysis, the whole data were cleaned and the doubly entered to minimize data entry error. Then, data were exported to Statistical Package for Social Sciences (SPSS) 16.0 version for analysis. For uniform scoring of items of five point Likert scale response format was used; negatively worded items were reversed.

Data were analyzed using SPSS version 16.0 and descriptive analysis was used to describe the percentages and number distributions of the respondents by socio-demographic characteristics, communication factors, past behaviours, cues to action and the main constructs of EPPM. Furthermore, bivariate and multivariable logistic regression analyses were used to identify factors that affect message responses using forward variable selection technique. All explanatory variables that were associated with the outcome variable in bivariate analysis with p-value of 0.25 or less were included in the initial logistic models. The crude and adjusted odds ratios together with their corresponding $95 \%$ confidence intervals were computed. In addition to this, for interval scale independents, unstandedized and standedized beta coeffecients was computed and interpreprated accordingly. A P-value $<0.05$ was considered to declare a result as statistically significant in this study. To traingulate the quantitative findings, qualitative data response were 
transcribed in Amharic and translated to English and the main response was reported using narrative and mentioned in direct quotation.

\section{Ethical consideration}

Prior to data collection, a formal letter was obtained from the ethical clearance committee of Jimma University and submitted to each college. Participant's right to self-determination and autonomy were respected. In order to protect the confidentiality of the information, names and ID numbers was not recorded on the questionnaire and privacy was maintained by independently answering the questionnaire.

\section{Result}

\section{Socio-economic and demographic characteristics of the respondents}

Three hundred ninety seven respodents participated in the study with overall response rate of $94.2 \%$. Accordingly, more than half, 238 (59.9\%), of the respondents were females. The mean age of the respondents was $19.3 \pm 1.7$ years (Table 1 ).

\section{Knowledge about HIV/AIDS}

Knowledge about HIV transmission: The study revealed that all the respondents have heard of HIV/AID. With regard to the transmission of the virus, 377 (95.0\%) of the respondents answered unprotected sex trasmists HIV and, 342 (86.1\%) of the respondents stated that sharing sharp instrument transmits the virus. Regarding the knowledge of mothers to child transmission of HIV, the majority of the respondents, $320(80.6 \%)$ knew that the virus transmits during delivery.

The study also indicated that there were some misconceptions regarding HIV/AIDS transmission. For instance, 220 (55.4\%) of the respondent believed that curse of God/supernatural means transmits HIV/AIDS followed by mosquitoe bite transmits HIV/AIDS 55 (13.9\%). Furthermore, some respondents also attributed the cause of HIV/AIDS to sharing food with HIV positive person can transmit the virus (Table 2).

Knowledge about HIV prevention: Concerning the knowledge of HIV/AIDS prevention method is concerned, 391 (98.5\%), of the respondents heard of HIV/AIDS prevention methods. Specifically, majority, 315 (79.3\%), of the respodent stated abstinience and condom use was stated by 292 (73.6\%). With regard to VCT, $344(86.6 \%)$ of the respondent stated that VCT help to know ones own HIV status. Similarly, 364 (91.7\%) of the respondent reported that limiting sexual partner to one prevents HIV/AIDS.

Accordingly, the comprehensive knowledge among the respondents was $337(84.9 \%)$.

\section{Communication factors}

Source of HIV/AIDS information: Regarding sources of information about HIV/AIDS, $320(80.6 \%)$ of the respondents were reported health insititutions while $17(4.3 \%)$ reported were heared from their spouse (Table 3).

Preference of source of information and channels for information: Table 4 shows the preference of source of and channels for HIV/AIDS message. Consequently, 263 (66.2\%) of the respondents were preferred health institution followed by $142(35.8 \%)$ that were preferred school/teachers. Regarding the preference of channel, more than three fourth, $309(77.8 \%)$, of the respondents were preferred television followed by radio which was accounts 272 (68.5\%).

\section{Messages and message appeals}

Table 5 presents frequently heard messages, specific messages heard of/seen and preferred message appeals for HIV/AIDS prevention. Accordingly, $166(41.8 \%)$ of the respondents were knew about the existence of mini media in their compound. With regard to specific messages heard of/seen, 358 (90.2\%) of the respondents were heard of value your life and let us fight HIV together while live and die reported by $227(57.2 \%)$ as a least to be heard.

Concerning the interest of the respondents on message appeals, $349(87.9 \%)$ respondents were liked factual message appeals through education which mainly focuses on transmission and prevention aspects followed by dramatic/funny message appeals which are full of entertainment and comic jokes which was account 331 (83.4\%).

\section{Perception towards HIV/AIDS}

Perception towards HIV and its prevetion methods were assessed

\begin{tabular}{|c|c|c|c|}
\hline Variables & Categories & Frequency & Percent (\%) \\
\hline \multirow{3}{*}{ College name } & HPTC & 205 & 51.6 \\
\hline & HTTC & 98 & 24.7 \\
\hline & $\mathrm{HCHS}$ & 94 & 23.7 \\
\hline \multirow{3}{*}{ Class year } & First year & 204 & 51.4 \\
\hline & Second year & 103 & 25.9 \\
\hline & Third year & 90 & 22.7 \\
\hline \multirow{2}{*}{ Sex } & Female & 238 & 59.9 \\
\hline & Male & 159 & 40.1 \\
\hline \multirow{3}{*}{ Age } & $15-19$ & 221 & 55.6 \\
\hline & $20-24$ & 171 & 43.1 \\
\hline & $25-29$ & 5 & 1.3 \\
\hline \multirow{2}{*}{ Previous residence } & Urban & 239 & 60.2 \\
\hline & Rural & 158 & 39.8 \\
\hline \multirow{3}{*}{ Marital status } & Single & 368 & 92.7 \\
\hline & Married & 27 & 6.8 \\
\hline & Divorced & 2 & 0.5 \\
\hline \multirow{4}{*}{$\begin{array}{l}\text { Religion of } \\
\text { respondent }\end{array}$} & Protestant & 255 & 64.2 \\
\hline & Catholic & 54 & 13.6 \\
\hline & Orthodox & 52 & 13.1 \\
\hline & Muslim & 36 & 9.1 \\
\hline \multirow{6}{*}{$\begin{array}{l}\text { Ethnicity of } \\
\text { respondent }\end{array}$} & Hadiya & 233 & 58.7 \\
\hline & Guraghe & 53 & 13.4 \\
\hline & Kembata & 51 & 12.8 \\
\hline & Silte & 26 & 6.5 \\
\hline & Wolaita & 4 & 1.0 \\
\hline & Others $^{*}$ & 30 & 7.6 \\
\hline \multirow{3}{*}{ Monthly income } & $\leq 200$ Eth.birr & 189 & 47.6 \\
\hline & 201-300 Eth.birr & 126 & 31.7 \\
\hline & $\geq 301$ Eth.birr & 82 & 20.7 \\
\hline \multirow{4}{*}{$\begin{array}{l}\text { With whom you } \\
\text { currently live? }\end{array}$} & With friends (rent house) & 143 & 36.0 \\
\hline & Alone (rent house) & 133 & 33.5 \\
\hline & With family & 119 & 30.0 \\
\hline & Others $^{* *}$ & 2 & 0.5 \\
\hline
\end{tabular}

"Amara, Oromo, Kafa, Sidama, Gedio, Sidama, Deworo, Tigre, konso, Alaba, Gidole, Kulo, Hamer. "Uncles, aunts or blood relatives. "HPTC- hosanna poly technic college, HTTC- hosanna teachers training college, HCHS- Hosanna College of health sciences.

Table 1: Socio- demographic characteristics of the respondents, Hosanna Colleges, Hadiya zone, SNNPR, Ethiopia, March 2012 ( $N=397)$. 


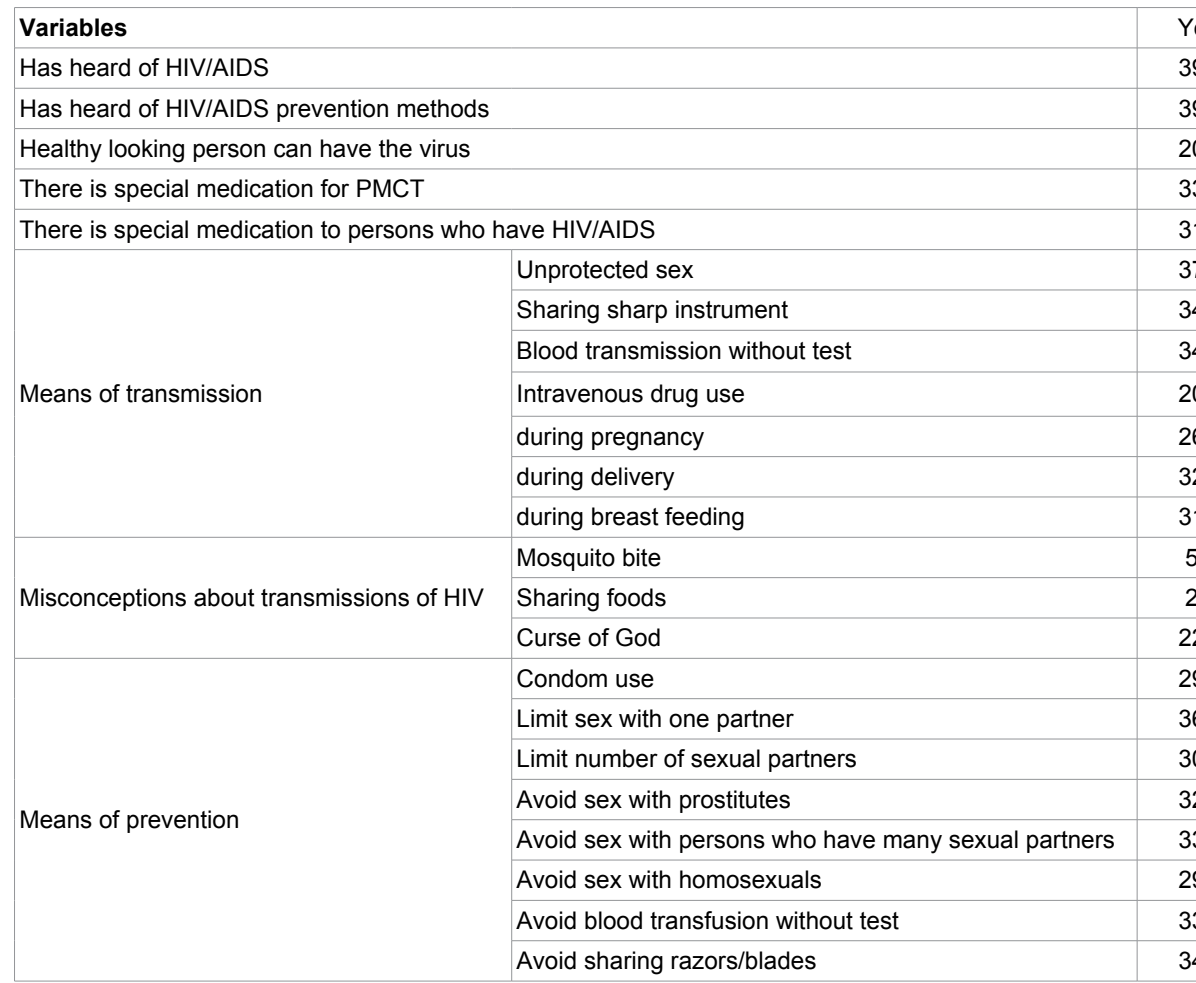

\begin{tabular}{|c|c|c|c|c|c|}
\hline Yes & $\%$ & No & $\%$ & DK & $\%$ \\
\hline 397 & 100.0 & 0 & 0.0 & 0 & 0.0 \\
\hline 391 & 98.5 & 6 & 1.5 & 0 & 0.0 \\
\hline 201 & 50.6 & 138 & 34.8 & 58 & 14.6 \\
\hline 335 & 84.4 & 35 & 8.8 & 27 & 6.8 \\
\hline 310 & 78.1 & 49 & 12.3 & 38 & 9.6 \\
\hline 377 & 95.0 & 20 & 5.0 & 0 & 0.0 \\
\hline 342 & 86.1 & 55 & 13.9 & 0 & 0.0 \\
\hline 340 & 85.6 & 57 & 14.4 & 0 & 0.0 \\
\hline 203 & 51.1 & 194 & 48.9 & 0 & 0.0 \\
\hline 269 & 67.8 & 99 & 24.9 & 29 & 7.3 \\
\hline 320 & 80.6 & 55 & 13.9 & 22 & 5.5 \\
\hline 311 & 78.3 & 51 & 12.8 & 35 & 8.8 \\
\hline 55 & 13.9 & 289 & 72.8 & 53 & 13.4 \\
\hline 27 & 6.8 & 358 & 90.2 & 12 & 3.0 \\
\hline 220 & 55.4 & 123 & 31.0 & 54 & 13.6 \\
\hline 292 & 73.6 & 73 & 18.4 & 32 & 8.1 \\
\hline 364 & 91.7 & 33 & 8.3 & 0 & 0.0 \\
\hline 302 & 76.1 & 95 & 23.9 & 0 & 0.0 \\
\hline 327 & 82.4 & 70 & 17.6 & 0 & 0.0 \\
\hline 333 & 83.9 & 64 & 16.1 & 0 & 0.0 \\
\hline 290 & 73.0 & 107 & 27.0 & 0 & 0.0 \\
\hline 336 & 84.6 & 61 & 15.4 & 0 & 0.0 \\
\hline 344 & 86.6 & 53 & 13.4 & 0 & 0.0 \\
\hline
\end{tabular}

'DK - I Don't Know.

Table 2: Frequency of the respondents' knowledge about HIVIAIDS transmission, prevention and some misconceptions in Hosanna Colleges, SNNPR, Ethiopia, March $2012(\mathrm{~N}=397)$

as perceived threat to and efficacy of HIV/AIDS of the recommended responses as well. Table 6 presents perception of respondents to HIV and its prevention methods.

Accordingly, respondents' perceived susceptibility to HIV/AIDS, $218(54.9 \%)$ of the respondents were lie on $1^{\text {st }}$ and $2^{\text {nd }}$ quartile scoring less than or equal to 27 from 45 which shows relatively low susceptibility score. Regarding perceived severity of HIV/AIDS, 205 (51.6\%) of the respondents were lie on $1^{\text {st }}$ and $2^{\text {nd }}$ quartile scoring less than or equal to 26 from 40 which shows relatively low severity score and the percision of score lies in between 24-26 out of 40. Regarding respondent's both perceived self efficacy and response efficacy of condom use to prevent HIV/AIDS, 208 (52.4\%) and 210 (52.9\%) of the respondents were lie on $1^{\text {st }}$ and $2^{\text {nd }}$ quartile respectively and their score was relatively good. The percision of score lies for self efficacy was in between 51-65 out of 80 and response efficacy was 35-45 out of 50. In case of each behavior the result was consistent.

As far as respondent's perceived threat and efficacy were considered, summed perceived threat from HIV/AIDS which was obtained from a sum of perceived susceptibility and severity, and summed perceived efficacy which was obtained from perceived self efficacy and response efficacy since its calculation was obtained from other variables while respondents who were found in efficacy appraisal are slightly higher quartiles than those in threat appraisals having an average quartile score of $50.1 \%$ and $52.9 \%$ respectively.

Taking presence of cues to HIV and condom use as prevention methods into consideration, different sources/conditions in last few months, about 155 (39.0\%) of the respondents were found in first quartile having the score less than or equal to $4 / 10$, this shows cues to action score is very low (Table 6).

\section{Resposnes to HIV/AIDS message}

As far as the response of respondents was concerned 191 (48.1\%) of respondents were under the category of danger control response where as $206(51.9 \%)$ of the respondents were under the category of fear control zone based on critical values (Table 7).

\section{Past risky and risk related sexual behaviours}

Sexual behaviors and condom use practice: As far as sexual behavior of the respondents was concerned, 134 (33.8\%) of the respondents had ever engaged on sex. Concerning condom use, out of the respondents who engaged on sex, 73 (54.5\%) respondents were used condom at least once in their history of sexual intercourse (Tables 8 and 9).

\section{The effect of Sociodemographic variables on message responses}

Looking into the effect of socio-demographic factors considering as individual differences in EPPM model, adjustment was made to see the effect on message responses in respondents by far the description of each concept considered as variables for prediction of responses in the model. College difference, religion, ethnicity, monthly income and previous residence had significant crude effect on message response. When adjusted with other sociodemographic variables only college difference and place of residence had statical significant effect on message response. Meaning, those respondents who previously resided in rural area were 0.39 times less likely had fear control responses for HIV prevention messages as compared to those who came from urban area with [AOR $(95 \%$ CI $)=0.39(0.21-0.74)]$. Similary, those respondents who were from HTTC as compared to HPTC had lowered odd of fear control responses for HIV prevention messages with [AOR $(95 \% \mathrm{CI})=0.37(0.19-0.72)]$. Those respondents who were from HTTC 


\begin{tabular}{|c|c|c|}
\hline Sources of information & Yes & $\%$ \\
\hline Health institutions & 320 & 80.6 \\
\hline School/Teacher & 270 & 68.0 \\
\hline Religious institutions & 223 & 56.2 \\
\hline Friends & 200 & 50.4 \\
\hline PLWHA & 152 & 38.3 \\
\hline Parents & 142 & 35.8 \\
\hline spouse & 17 & 4.3 \\
\hline Others $^{*}$ & 7 & 1.8 \\
\hline
\end{tabular}

*Repoter of news and youth clubs.

Table 3: Frequencies of the respondents' source of information for HIVIAIDS among Hosanna Colleges, SNNPR, Ethiopia ( $\mathrm{N}=397)$.

\begin{tabular}{|c|c|c|c|}
\hline \multicolumn{2}{|r|}{ Variables } & Yes & $\%$ \\
\hline \multirow{7}{*}{ Preferred sources } & Health institutions & 263 & 66.2 \\
\hline & School/Teacher & 142 & 35.8 \\
\hline & Religious institutions & 136 & 34.3 \\
\hline & PLWHA & 84 & 21.2 \\
\hline & Friends & 63 & 15.9 \\
\hline & Parents & 48 & 12.1 \\
\hline & Spouse & 5 & 1.3 \\
\hline \multirow{5}{*}{ Preferred channels } & Television & 309 & 77.8 \\
\hline & Radio & 272 & 68.5 \\
\hline & Peer discussions & 255 & 64.2 \\
\hline & Printed materials: posters, leaflets, poem & 190 & 47.9 \\
\hline & Others $^{*}$ & 11 & 2.8 \\
\hline
\end{tabular}

"School media

Table 4: Frequencies of the preferred source of and channels for information about HIVIAIDS among respondents of Hosanna Colleges, SNNPR, Ethiopia (N=397).

\begin{tabular}{|c|c|c|c|c|c|}
\hline \multicolumn{2}{|l|}{ Variables (messages) } & Yes & $\%$ & No & $\%$ \\
\hline \multicolumn{2}{|c|}{ There is media in our compound } & 166 & 41.8 & 231 & 58.2 \\
\hline \multirow{4}{*}{$\begin{array}{l}\text { Frequently heard } \\
\text { message/behavior }\end{array}$} & Abstenince & 213 & 53.7 & 184 & 46.3 \\
\hline & Being faithful & 139 & 35.0 & 258 & 65.0 \\
\hline & Using condom & 178 & 44.8 & 219 & 55.2 \\
\hline & VCT/PIHCT & 187 & 47.1 & 210 & 52.9 \\
\hline \multirow{8}{*}{$\begin{array}{l}\text { Specific messages } \\
\text { heard of/seen }\end{array}$} & Value your life & 358 & 90.2 & 39 & 9.8 \\
\hline & let us fight HIVIAIDS together & 358 & 90.2 & 39 & 9.8 \\
\hline & Care and support for HIVP & 332 & 83.6 & 65 & 16.4 \\
\hline & let us take care of each other & 332 & 83.6 & 65 & 16.4 \\
\hline & I care, do you? & 326 & 82.1 & 71 & 17.9 \\
\hline & $\begin{array}{l}\text { Abstain from sex before } \\
\text { marriage }\end{array}$ & 289 & 72.8 & 108 & 27.2 \\
\hline & Stop stigma \& discrimination & 282 & 71.0 & 115 & 29.0 \\
\hline & Live and die & 227 & 57.2 & 170 & 42.8 \\
\hline \multirow{7}{*}{$\begin{array}{l}\text { Preferred message } \\
\text { appeals }\end{array}$} & Dramatic/funny & 331 & 83.4 & 66 & 16.6 \\
\hline & Factual through education & 349 & 87.9 & 48 & 12.1 \\
\hline & Fear arousal messages & 138 & 34.8 & 259 & 65.2 \\
\hline & Two sided message & 265 & 66.8 & 132 & 33.2 \\
\hline & One sided message & 124 & 31.2 & 273 & 68.8 \\
\hline & Positive message & 195 & 49.1 & 202 & 50.9 \\
\hline & Negative message & 137 & 34.5 & 260 & 65.5 \\
\hline
\end{tabular}

Table 5: Frequencies of the frequently heard behaviours, specific messages heard/ seen and Preferred message appeal among respondents of Hosanna colleges, SNNPR, Ethiopia ( $\mathrm{N}=397$ ).

were 0.37 times less likely to be in fear control/unintended response than HPTC (Table 10).

\section{The effect of EPPM model constructs on message responses}

Taking EPPM constructs as a predictor of message response standardized and unstandardized beta coffecients were calculated. Following that, each of the constructs effect was seen before and after adjustment and the rest parts were summarized in Table 11.

Perceived susceptibility to HIV/AIDS had a statistical significant effect on fear control response with beta coffiecient [standerdized $\beta(95 \% \mathrm{CI})=1.25(1.69-7.19)]$.i.e. From the model, the coefficient of susceptibility score implies that being in fear control response results in average increase in susceptiblity score by 1.25 . Perceived severity to HIV/AIDS had a statistical significant effect on fear control response with beta coffiecient [standerdized $\beta(95 \% \mathrm{CI})=1.69(2.10-13.94)$ ]. From the model, the coefficient of severity score implies that being in fear control response results in average increase in severity score by 1.69 .

Perceived self efficacy of recommended responses for HIV/AIDS prevention had a statistical significant effect on fear control responses for using condom and VCT with beta coefficients [standardized $\beta(95 \%$ $\mathrm{CI})=-1.24(0.14-0.60)]$. From the model, for instance, the coefficient of self efficacy for abstinence score implies that being in fear control response results in average reduction in self-efficacy score by 0.85 . In contrary, overall self efficacy had no significant adjusted effect when adjusted by other constructs (Table 11).

Response efficacy of recommended responses for HIV/AIDS prevention had a statistical significant effects on fear control responses for using condom with beta coefficients of fear control responses [standardized $\beta(95 \% \mathrm{CI})=-1.86(0.05-0.51)]$. Interpreted as, from the model, for instance, the coefficient of response efficacy score for using condom implies that being in fear control response results in average reduction in response efficacy score by 1.86. Like overall self efficacy, the overall perceived response efficacy had no significant adjusted effect when adjusted by other constructs.

\section{The effect of communication factors on message response}

Communication factors/distal factors were considered as a predictor message response for prediction of message response. The crude and adjusted effects of factors like source of information, preferred source, message appeals and channels, frequently heard behaviours and specific messages heard of/seen were calculated.

Those respondents who preferred fear arousal appeal messages were 1.93 times more likely in fear control response as compared to those respondents who didn't prefer fear arousal appeal message with [AOR $(95 \%$ CI $)=1.93(1.05-3.57)]$. Those respondents who didn't heard the message avoid stigma and discrimination were 2.37 times more likely to exprience fear control responses for HIV as compared to avoid stigma and discrimination with [AOR $(95 \% \mathrm{CI})=2.37(1.33$ $4.24)]$. In parallel speaking, hearing the message avoid stigma and discrimination leads individuals to be danger control response (Table 12).

\section{The effect of past behaviors on message responses}

Past behaviors taken as variables of predictor of message responses by considering risky behaviors related to HIV, like ever had sex, age at first sex, condom use, frequency of condom use, kind of sex partner, experience of testing after sexual intercourse and ever testing, and decision to have sex now and for future (Table 8). The crude and adjusted effects of these behaviors were seen. Only kind of sexual partner and ever tested in their life showed significant crude effect on message responses. When adjustment was made with other HIV risk 
Page 7 of 11

\begin{tabular}{|c|c|c|c|c|c|c|c|c|c|}
\hline \multirow{3}{*}{ Components/constructs } & \multicolumn{6}{|c|}{ Quartiles } & & & \multirow{3}{*}{ Scale range } \\
\hline & \multicolumn{2}{|c|}{$1^{\text {st }}$} & \multicolumn{2}{|c|}{$2^{\text {nd }}$} & \multicolumn{2}{|c|}{$3^{\text {rd }}$} & \multicolumn{2}{|c|}{$4^{\text {th }}$} & \\
\hline & $\mathbf{N}$ & Score & $\mathbf{N}$ & Score & $\mathbf{N}$ & Score & $\mathbf{N}$ & Score & \\
\hline P. susceptibility to HIV & 110 & 22 & 108 & 27 & 88 & 31 & 91 & 45 & $9-45$ \\
\hline P. severity of HIV & 99 & 21 & 106 & 26 & 94 & 30 & 98 & 40 & $8-40$ \\
\hline P. efficacy & 97 & 86 & 113 & 98 & 91 & 107 & 96 & 130 & $26-130$ \\
\hline P. threat & 114 & 45 & 85 & 52 & 109 & 60 & 89 & 85 & $17-85$ \\
\hline P. self efficacy of condom use & 104 & 5 & 100 & 12 & 109 & 17 & 84 & 25 & $5-25$ \\
\hline P. response efficacy of condom use & 115 & 8 & 142 & 11 & 68 & 13 & 72 & 15 & 3-15 \\
\hline Cues to action & 155 & 4 & 60 & 5 & 95 & 7 & 87 & 10 & $0-10$ \\
\hline
\end{tabular}

- P: perceived.

Table 6: showing descriptive statistics for constructs of EPPM by their scale range with their respective weights of the respondents in Hosanna Colleges, Southern, Ethiopia. ( $\mathrm{N}=397)$.

\begin{tabular}{|c|c|c|}
\hline Behaviour & Danger control response(CV+) & Fear control response(CV-) \\
\hline Condom use & $191(48.1 \%)$ & $206(51.9 \%)$
\end{tabular}

Table 7: Category of danger control response.

\begin{tabular}{|c|c|c|c|c|c|c|c|}
\hline \multirow{2}{*}{\multicolumn{2}{|c|}{ Variables }} & \multicolumn{2}{|c|}{ Danger control } & \multicolumn{2}{|c|}{ Fear control } & \multicolumn{2}{|c|}{ Total } \\
\hline & & \multirow{2}{*}{\begin{tabular}{|l|} 
No \\
102 \\
\end{tabular}} & \multirow{2}{*}{\begin{tabular}{|l|}
$\%$ \\
25.7
\end{tabular}} & \multirow{2}{*}{\begin{tabular}{|l|} 
No \\
32 \\
\end{tabular}} & \multirow{2}{*}{\begin{tabular}{|l|}
$\%$ \\
8.1 \\
\end{tabular}} & \multirow{2}{*}{\begin{tabular}{|l|} 
No \\
134 \\
\end{tabular}} & \multirow{2}{*}{\begin{tabular}{|l|}
$\%$ \\
33.8
\end{tabular}} \\
\hline Ever engared in Sev (N-307) & Yes & & & & & & \\
\hline Ever engaged in sex (IV-39i) & No & 212 & 3.4 & 51 & 12.8 & 263 & 66.2 \\
\hline \multirow{3}{*}{ Age at first sex $(N=134)$} & $10-14$ & 8 & 6.0 & 1 & 0.7 & 9 & 6.7 \\
\hline & $15-19$ & 77 & 57.5 & 24 & 17.9 & 101 & 75.4 \\
\hline & $20-24$ & 17 & 12.7 & 7 & 5.2 & 24 & 17.9 \\
\hline \multirow{6}{*}{ Kind of sexual partner $(\mathrm{N}=134)$} & Causal partner & 39 & 29.1 & 13 & 9.7 & 52 & 38.8 \\
\hline & Class mate & 23 & 17.2 & 4 & 3.0 & 27 & 20.2 \\
\hline & Teacher & 5 & 3.7 & 3 & 2.2 & 8 & 5.9 \\
\hline & Spouse & 14 & 10.4 & 6 & 4.5 & 20 & 14.9 \\
\hline & Sexual partner & 13 & 9.7 & 4 & 3.0 & 17 & 12.7 \\
\hline & Others & 8 & 6.0 & 2 & 1.5 & 10 & 7.5 \\
\hline \multirow{3}{*}{ No of sexual partner sofar $(\mathrm{N}=134)$} & Only one & 50 & 37.3 & 16 & 11.9 & 66 & 49.2 \\
\hline & Only two & 23 & 17.2 & 8 & 6.0 & 31 & 23.2 \\
\hline & $3 \&$ more & 29 & 21.6 & 8 & 6.0 & 37 & 27.6 \\
\hline \multirow{2}{*}{ Engaged on sex in last 12 month $(\mathrm{N}=134)$} & Yes & 93 & 69.4 & 32 & 23.9 & 125 & 93.3 \\
\hline & No & 9 & 6.7 & 0 & 0.0 & 9 & 6.7 \\
\hline \multirow{3}{*}{ No of sexual partner sex in last 12 months $(\mathrm{N}=125)$} & Only one & 61 & 48.8 & 20 & 16.0 & 81 & 64.8 \\
\hline & Only two & 15 & 12.0 & 9 & 7.2 & 24 & 19.2 \\
\hline & >Three & 17 & 13.6 & 3 & 2.4 & 20 & 16.0 \\
\hline \multirow{3}{*}{ Number of regular sexual partner sex in last 12 months $(N=125)$} & Only one & 68 & 54.4 & 22 & 17.6 & 90 & 72.0 \\
\hline & Only two & 15 & 12.0 & 7 & 5.6 & 22 & 17.6 \\
\hline & $\geq$ Three & 10 & 8.0 & 3 & 2.4 & 13 & 10.4 \\
\hline \multirow{6}{*}{ Kind of sexual Partner in last sex $(\mathrm{N}=125)$} & Causal partner & 45 & 36.0 & 10 & 8.0 & 55 & 44.0 \\
\hline & Class mate & 16 & 12.8 & 4 & 3.2 & 20 & 16.0 \\
\hline & Teacher & 11 & 8.8 & 3 & 2.4 & 14 & 11.2 \\
\hline & Spouse & 13 & 13.4 & 9 & 7.2 & 22 & 20.6 \\
\hline & Sexual partner & 12 & 9.6 & 5 & 4.0 & 17 & 13.6 \\
\hline & Others & 5 & 4.0 & 1 & 0.8 & 6 & 4.8 \\
\hline \multirow{2}{*}{ have sexual partner currently $(\mathrm{N}=134)$} & Yes & 59 & 44.0 & 20 & 14.9 & 79 & 58.9 \\
\hline & No & 43 & 32.1 & 12 & 9.0 & 55 & 41.1 \\
\hline \multirow{3}{*}{ No of current sexual partner $(N=79)$} & 1 only & 47 & 59.5 & 18 & 22.8 & 65 & 82.3 \\
\hline & 2 only & 9 & 11.3 & 1 & 1.3 & 10 & 12.6 \\
\hline & $\geq 3$ & 3 & 3.8 & 1 & 1.3 & 4 & 5.1 \\
\hline
\end{tabular}

Table 8: Showing frequency of respondents' past sexual behaviors by responses (danger control or fear control) among Hosanna Colleges, SNNPR, Ethiopia, March, 2012.

related behaviours, only ever used condom in last sex became significant to message responses. Respondents who ever used condom in last sex were 0.04 times less likely to experience fear control responses for HIV prevention messages as compared to who never used condom in last sex with adjusted odds ratio [AOR $(95 \% \mathrm{CI})=0.04(0.00-0.65)]$ (Table 13).

\section{Final logistic model for prediction of message responses}

In final fitting model prediction part, all the variables which were significant in bivariate analysis such as sociodemographic, past risky \& risk related behaviors, main constructs of EPPM and distal factors were adjusted to predict message response using forward Likelihood regression method: the main constructs of the EPPM model left over 


\begin{tabular}{|c|c|c|c|c|c|c|c|}
\hline \multirow{2}{*}{\multicolumn{2}{|c|}{ Variables }} & \multicolumn{2}{|c|}{ Danger control } & \multicolumn{2}{|c|}{ Fear control } & \multicolumn{2}{|c|}{ Total } \\
\hline & & No & $\%$ & No & $\%$ & No & $\%$ \\
\hline \multirow{2}{*}{ Ever used condom $(\mathrm{N}=134)$} & Yes & 59 & 44.0 & 14 & 10.5 & 73 & 54.5 \\
\hline & No & 43 & 32.1 & 18 & 13.4 & 61 & 45.5 \\
\hline \multirow{2}{*}{ Condom use at first sex $(N=134)$} & Yes & 50 & 37.4 & 16 & 11.9 & 66 & 49.3 \\
\hline & No & 52 & 38.8 & 16 & 11.9 & 68 & 50.7 \\
\hline \multirow{2}{*}{ Condom use in last sex $(\mathrm{N}=125)$} & Yes & 47 & 35.1 & 15 & 11.2 & 62 & 46.3 \\
\hline & No & 55 & 41.0 & 17 & 12.7 & 72 & 53.7 \\
\hline \multirow{3}{*}{ Frequency of Condom use in last sex $(\mathrm{N}=62)$} & Sometimes & 19 & 30.6 & 10 & 16.1 & 29 & 46.7 \\
\hline & Usually & 12 & 19.4 & 4 & 6.5 & 16 & 25.9 \\
\hline & Consistently & 16 & 25.8 & 1 & 1.6 & 17 & 37.4 \\
\hline
\end{tabular}

Table 9: Showing frequency of respondents' condom use by responses (danger control or fear control) among Hosanna Colleges, SNNPR, Ethiopia, March, 2012.

\begin{tabular}{|c|c|c|c|c|c|}
\hline \multicolumn{2}{|c|}{ Variable } & No & $\%$ & $\operatorname{COR}(95 \% \mathrm{Cl})$ & AOR(95\% Cl) \\
\hline \multirow{3}{*}{ College name } & HPTC & 205 & 51.6 & 1 & 1 \\
\hline & $\mathrm{HCHS}$ & 94 & 23.7 & $0.77(0.31-1.07)$ & $0.64(0.33-1.18)$ \\
\hline & HTTC & 98 & 24.7 & $0.43(0.22-0.83)^{*}$ & $0.37(0.19-0.72)^{*}$ \\
\hline \multirow{4}{*}{ Religion } & Protestant & 255 & 64.2 & 1 & 1 \\
\hline & Orthodox & 52 & 13.1 & $1.00(0.48-2.07)$ & $1.49(0.61-3.63)$ \\
\hline & Muslim & 54 & 13.6 & $0.83(0.14-1.00)^{*}$ & $0.49(0.13-1.84)$ \\
\hline & Catholic & 36 & 9.1 & $2.10(1.00-4.43)^{*}$ & $2.00(0.90-4.43)$ \\
\hline \multirow{6}{*}{ Ethnicity } & Hadiya & 233 & 58.7 & 1 & 1 \\
\hline & Kembata & 51 & 12.8 & $0.38(0.16-0.95)^{*}$ & $0.51(0.19-1.40)$ \\
\hline & Guraghe & 53 & 13.4 & $0.59(0.27-1.28)$ & $0.76(0.26-2.23)$ \\
\hline & Silte & 26 & 6.5 & $0.24(0.06-1.28)$ & $0.73(0.10-5.25)$ \\
\hline & Wolaita & 4 & 1.0 & $2.88(0.40-20.92)$ & $5.00(0.59-42.57)$ \\
\hline & Others" & 30 & 7.6 & $0.44(0.15-1.32)$ & $0.65(0.20-2.10)$ \\
\hline \multirow{2}{*}{ Previous residence } & Urban & 239 & 60.2 & 1 & 1 \\
\hline & Rural & 158 & 39.8 & $0.41(0.23-0.70)^{*}$ & $0.39(0.21-0.74)^{*}$ \\
\hline \multirow{3}{*}{ Monthly income } & $\leq 200$ & 189 & 47.6 & 1 & 1 \\
\hline & $201-300$ & 126 & 31.7 & $0.48(0.27-0.87)^{*}$ & $0.67(0.26-1.77)$ \\
\hline & $\geq 301$ & 82 & 20.7 & $0.51(0.26-0.51)^{*}$ & $0.78(0.32-1.92)$ \\
\hline
\end{tabular}

"statistically significant at $p$ value $<0.05,1$ is Odds ratio for reference category

NB. Variables indicated in the above table are significant in crude or/and adjusted OR but those which are not significant in either of/ both cases are not indicated in the table.

Table 10: Regression analysis to see the effect of sociodemographic variables in response categories of the respondents in Hosanna Colleges, Southern Ethiopia, March 2012.

\begin{tabular}{|c|c|c|}
\hline \multirow{2}{*}{ Constructs } & \multicolumn{2}{|c|}{ Regression coefficients } \\
\cline { 2 - 3 } & Unstandardized $\boldsymbol{\beta}(\mathbf{9 5} \% \mathbf{C I})$ & Standardized $\boldsymbol{\beta}(\mathbf{9 5} \% \mathbf{C l})$ \\
\hline P. susceptibility & $0.14(1.10-1.20)^{*}$ & $1.25(1.69-7.19)^{*}$ \\
\hline P. severity & $0.12(1.08-1.18)^{*}$ & $1.69(2.10-13.94)^{*}$ \\
\hline P. self efficacy of condom use & $-0.81(0.88-0.96)^{*}$ & $-0.91(0.22-0.73)^{*}$ \\
\hline P. response efficacy of condom use & $-0.24(0.72-0.86)^{*}$ & $-1.86(0.05-0.51)^{*}$ \\
\hline
\end{tabular}

'Statistically significant at $p$. value $<0.05$.

NB. Variables indicated in the above table are significant in crude or/and adjusted OR only but those which are not significant in both cases are not indicated in the table.

Table 11: Regression coefficients $(\beta)$ to see the effect of EPPM constructs in message response categories of the respondents in Hosanna Colleges, SNNPR, Ethiopia, March 2012

in the final model. Predicted final model (fear control as a variable of interest) $=14.58+1.07$ (perceived susceptibility) +1.65 (perceived severity)-0.96 (self efficacy)-1.21 (response efficacy). The model explained about $66.3 \%$ of prediction of message response (fear control as a variable of interest) among respondents learning in the three college with goodness of fit of the model $\left(\mathrm{X}^{2} / \mathrm{df}=8.43 / 8\right.$, $\mathrm{p}$ value $\left.=0.21\right)$ (Table 14).

\section{Discussion}

This study tried to assess HIV prevention message response in terms of the perception of individuals to threat acquiring, seriousness and averting efficaciousness using EPPM model. According to EPPM model, individuals' perceived susceptibility to and severity of a disease condition is a baseline to take a next step to avert this condition by far helps to develop self confidence to stand for tackling this problem which inturn helps individuals to go through the effective method which adds value for his/her health (response efficacy) provided that people are already awared in a particular health threat since the model best works in situation where respondents have high level of awareness than motivational variables $[10,13]$.

The result of this study also congruent with this assumption being high knowledge level was $84.9 \%$ but as compared to other findings, 


\begin{tabular}{|c|c|c|c|c|c|}
\hline \multicolumn{2}{|l|}{ Variables } & No & $\%$ & $\operatorname{COR}(95 \% \mathrm{Cl})$ & AOR(95\%Cl) \\
\hline \multirow{2}{*}{ Frequently condom use } & Yes & 179 & 44.8 & $0.60(0.36-0.99)^{*}$ & $0.63(0.37-1.07)$ \\
\hline & No & 219 & 55.2 & 1 & 1 \\
\hline \multirow{2}{*}{ Fear arousal appeal } & Yes & 138 & 34.8 & $1.41(0.23-0.73)^{*}$ & $1.93(1.05-3.57)^{*}$ \\
\hline & No & 259 & 65.2 & 1 & 1 \\
\hline \multirow{2}{*}{ Positive message } & Yes & 195 & 49.1 & $0.58(0.36-0.96)^{*}$ & $1.26(0.74-2.15)$ \\
\hline & No & 202 & 50.9 & 1 & 1 \\
\hline \multirow{2}{*}{ Value your life } & Yes & 358 & 90.2 & 1 & 1 \\
\hline & No & 39 & 9.8 & $2.06(1.01-4.21)^{*}$ & $1.46(0.67-3.18)$ \\
\hline \multirow{2}{*}{ Avoid stigma and discrimination } & Yes & 282 & 71.0 & 1 & 1 \\
\hline & No & 115 & 29.0 & $3.17(1.92-5.24)^{*}$ & $2.37(1.33-4.24)^{*}$ \\
\hline \multirow{2}{*}{ Let us fight each others } & Yes & 332 & 83.6 & 1 & 1 \\
\hline & No & 65 & 16.4 & $2.67(1.33-5.35)^{*}$ & $0.76(0.38-1.55)$ \\
\hline
\end{tabular}

statistically significant at $\mathrm{p}$ value $<0.05,1$ is Odds ratio for reference category.

NB. Variables indicated in the above table are significant in crude or/and adjusted OR only but those which are not significant in both cases are not indicated in the table.

Table 12: Regression analysis of effect of distal factors on message response categories of the respondents in Hosanna Colleges, Southern Ethiopia, March 2012.

the result is inconsistent with or higher than the findings of other studies conducted in Sub Saharan Africa [1,2] and the, EDHS, 2010 conducted in Ethiopia [14]. In support of this view in qualitative study almost all the informants and discussants said that "HIV knowledge in its existence, transmission and prevetion is universal." This could be due to the urban nature of the study area that increased accessibility to information and also might be improvement was observed with different levels of intervention.

According to the findings of the study, perceived susceptibility to HIV/AIDS directly attached with fear control response which in turn reduces the protective effects of the individuals increasing the likelihood of fear control response. Similarly, other several studies also ascertained that although teenagers and college students are knowledgeable about HIV/AIDS and its prevention strategies, the majority do not see themselves at risk for HIV/AIDS. For instance, a cross-sectional study conducted in Ethiopia on message response of Bahr dar university students were similar findings that a belief of personal perceived susceptibility to HIV risk in relation to condom use is low [15].

This study perceived severity of HIV/AIDS showed positive effect on fear control response which in turn reduces the protective effects of the individuals increasing the likelihood of fear control response. This finding also supported by qualitative finding in which one of the female respondents with age of 21 years said that "...when someone is hearing HIV messages like condom use, he/she rushes not to hear this old message especially young generation considering HIV as any disease like common cold." However, as compared to the finding of this study, the study conducted in Kenya at 244 university students indicated that almost all the students perceived HIV and AIDS to be very serious resulting in lack of variance in the measure [16]. The potential reason may be peoples are familiarized HIV as not to have immediate consequences rather it lasts long period.

In this study, over all perceived self efficacy of HIV/AIDS showed negative effect on fear control response which in turn enhances the protective effects of the individuals reducing the likelihood of fear control response which really parallels with the idea of EPPM model in message evaluation since directly linked with danger control responses. Similar to this study perceived self efficacy is the variable significantly predicting whether or not university students in Kenya use condoms to prevent HIV and AIDS infection [16]. This is similar in idea to the studies done in the United States indicate that youth- oriented prevention programs that exclusively promote abstinence do not reduce the risk of HIV infection [17].

In this study danger ccontrols had statistically significant higher number of cues to HIV information as compared to fear controls. The study done using HBM in Ethiopia on Haramaya university students on condom use and Butajira high school students on VCT use had stated similar effect of cues to condom use and VCT use revealing those individuals who have open discussion about HIV/AIDS with partners were more likely use condom and to be tested [18].

Colleges' difference had significantly associated fear control responses. Accordingly, being from Hosanna College of teachers' education had high significant positive association with danger control responses meaning the respondents in HTTC were practicing intended behavior as noted in findings of this study in comparative of the other three colleges involved. This finding also supported by qualitative finding in which being from Hosanna College of teachers' education, unlike to other colleges, showed highly strong HIV mainstreaming programs on account of having motivated staff members and highly committed NGO's like OSSA in contributing their share on prevention activities by providing health learning materials, condoms..., and participating on coffee ceremony which opens door for discussion how to use condom and other important issues related to HIV.

From the same college one of the female informants whose position was coordination in mainstreaming with age 23 said that "we have open discussion with students in a class, coffee ceremony and elsewhere when $H I V$ issues are raised with the aim of suppressing its prevalence as well as encouraging students to engage in prevetion activities provided that those hidden behaviors were already manifested and clearly discussed...." Unlike to this saying all the discussants who came from HPTC said that "we accept abstinence ....HIV/AIDS is the diseases of those individuals who are deviating from GOD's /ALLAHA'S law which is stated in Bible or Quran and for those who are going out of cultural tracks. So whether you teach or not, it is not our business because we are abstaining."

Regarding previous residence being rural resident is more significantly positively attached with intended responses as compared to urban residents. Similar to this finding, a cross-sectional study done in 2010 in Debre Berhan college on female students showed rural dwellers are less likely to be engaged in sexual intercourse and more abstinent groups as compared to urban [18]. The possible reason of higher significant acceptance of messages among rural residents compared to urban residents may be related fear of the threat in rural comers is attached with abstaining until marriage. 


\begin{tabular}{|c|c|c|c|c|c|}
\hline Variables & & No & $\%$ & $\operatorname{COR}(95 \% \mathrm{Cl})$ & $\operatorname{AOR}(95 \% \mathrm{Cl})$ \\
\hline \multirow{6}{*}{ Kind of sexual partner in last sex } & Causal & 52 & 38.8 & 1 & 1 \\
\hline & Classmate & 27 & 20.2 & $1.13(0.31-4.10)$ & $2.64(0.35-20.18)$ \\
\hline & Teacher & 8 & 5.9 & $1.23(0.29-5.23)$ & $1.26(0.17-9.61)$ \\
\hline & Spouse & 20 & 14.9 & $3.12(1.05-9.28)^{*}$ & $8.46(0.61-117.00)$ \\
\hline & Sexual & 17 & 12.7 & $1.88(0.54-6.53)$ & $2.63(0.13-51.39)$ \\
\hline & Others ${ }^{*}$ & 10 & 7.5 & $0.90(0.10-8.57)$ & 000(000--) \\
\hline \multirow{2}{*}{ Ever used condom last sex $(\mathrm{N}=134)$} & Yes & 62 & 46.3 & $0.57(0.25-1.26)$ & $0.04(0.00-0.65)^{\star}$ \\
\hline & No & 72 & 53.7 & 1 & 1 \\
\hline
\end{tabular}

"Statistically significant, "Uncles and aunts son, 1 is Odds ratio for reference category.

Table 13: Regression analysis to see the effect of past behaviour on message response categories of the respondents in Hosanna Colleges, Southern Ethiopia, March 2012

\begin{tabular}{|c|c|c|c|c|c|}
\hline Variables in the equation & B & & OR & & \\
\hline Perceived susceptibility & 1.07 & 0.02 & 2.93 & 1.21 & 7.10 \\
\hline perceived severity & 1.65 & 0.03 & 5.21 & 1.25 & 21.81 \\
\hline perceived self-efficacy & -0.96 & 0.03 & 0.38 & 0.16 & 0.92 \\
\hline perceived response efficacy & -1.21 & 0.02 & 0.30 & 0.11 & 0.83 \\
\hline Constant & 14.58 & 0.10 & $2.141 \mathrm{E} 6$ & & \\
\hline
\end{tabular}

Table 14: Multivariable logistic regression analysis for final fitted model prediction of message response among respondents of Hosanna colleges, SNNPR, Ethiopia, March, 2012.

Monthly income had no significant adjusted effect in message responses. This is contarary, to the study conducted in Addis Ababa in 2007 on risk sexual behavior of in school youths that showed significant positive risk protective effect of monthly income [18]. Corresponding to this findings, in qualitative part, one of the male informants from HCHS with age of 37 years said that "...those female students who came from poor families have high tendency to be engaged in multiple sexual partners and to have sex 'sugare dadi' with guys whose age is greater than themselves since the money given from this compus is 240 birr only, even which is not enough to buy 'salt', in this regard they are right... though what they are practicing is risk."

Respondents who did not hear abstinence message frequently had slightly higher adjusted odds of fear control than those heard abstinences message frequently. In other words, they are less protective than those who heard abstinence frequently. All the respondents' indepth interview said that since the students are in education we teach them frequently to abstain, in second place to be fathfulness but condom use solely recommended as last opition.

In this study being unaware of the message avoid stigma and discrimination in last six months had positive association with fear control responses. That means who heard the message were in danger control responses. But fear arousal appeal had positive effect in fear control responses which is congruent with the assumption of EPPM model which states fear is central variable which motivates individuals via developing defense motivation of threat. According to Witte, message should use the appropriate appeal to persuade receiver $[9,10,13]$. In support of this view in qualitative finding one informant with age 23 said that "...you know forbidden things are sweetest for human being. If you teach this generation by fear arousal message, they may not accept rather by drama, role play, phoem and other funny talks accepted and ours is also that."

The finding of this study revealed that risky behaviors related to HIV: condom use in last sex had highly positive relation with danger control responses when adjusted in their dista factors. Similar findings were documented studies done in United States that Youth-oriented prevention programs promoting correct and consistent use of condoms; reducing the number of sexual partners, broaden access to HIV testing and counseling and ensuring effective infection control intervention programs reduced the prevalence of diseases [1,2]. The current study used tested model for message response/evaluation as theoritical framework that outlines how to measure the components explicitly so that they are easily summarized. Qualitative and quantitative data were trianguted. May use for other researchers as baseline data/information since no local literature was stated in this critical value/discriminative scores. But, in reality, it is difficult to find individuals in no response zone even difficult to interpret in situation where an individual has high threat and high efficacy and vice versa in which their difference is zero (zero discriminative score). Those individuals in danger control zone, they may not actually perform the behavior which may lead to over reporting of safe sexual behaviors.

In conclusion, despite high proportion of college students were in danger control psychological responses there is current behavior gap of prevention of HIV/AIDS. As is, the main constructs had significantly associated with message responses particularly susceptibility to and severity of HIV/AIDS were directly attached with fear control responses, where as self efficacy and response efficacy to HIV prevention messages were directly linked with danger control response which is congruent with the assumption and general idea of EPPM model. Messages communicated on HIV/AIDS prevention methods encouraged college students response in heirarchial order of absteinance, faithfulness and condom use. Relative to other methods of prevention of HIV/AIDS college students' danger control responses towards condom use is low eventhough being in danger control encouraged condom use. The way how to deliver message (appeals) mostly determine its effectiveness in encouraging the acceptance of message particularly fear arousal appeal of messages produces fear control responses. Involvement of health personnels and TV channel is preffable source of information to students. Generally, the independent predictors of the message response were the main constructs of EPPM model either in acceptance or in rejection of message.

To colleges, message developers, HIV/AIDS prevention and control offices, researcher and any organizations working in the area of HIV/AIDS prevention should follow the following recommendations.

> Considerably intolerable numbers were below knowledge level, so, intensified IEC campaigns focusing on misconceptions 
of HIV transmission and prevention should be undertaken particularly among young peoples.

$>$ Should promote further efficacy oriented messages in relation to condom use particularly misconceptions about condom and mythical beliefs.

$>$ Messages focusing on real experience; facts with reasons, comic jocks and entertaining should be promoted for this young people.

> Health personnels, schools/teachers, religious leaders and PLWHA should be involved to be persuasive communication for convincing the students.

$>$ Fear appeal should not be used for the promotion of HIV/ AIDS messages

> Should have continuous IEC/BCC intervention programs since low perception of susceptibility and severity was observed.

Further studies, using the same model, should be conducted on message response of each behavior helps explicitly tailor the messges.

\section{Acknowledgements}

Our earnest gratitude goes to Public Health and Medical sciences college Jimma University for proper review and approval of this paper. We are happy to be in a position to thank Professor Witte for her invaluable contribution in locating us the source of questionnaires done on EPPM model and short and brief notes of the model as well. Our gratitude thanks goes to the three colleges to their contribution in providing us baseline information and coordinating students to fill the questionnaire at a time of data collection.we would also like to extend our gratitude to students of the three colleges for their patience to fill questionnaires and for their involvement in in focus group discussion to share information. Our special thanks also extended to Hadiya zone health bureau for financial support for this study.

\section{References}

1. UNAIDS (2008/ 2009) Report on the Global AIDS epidemic

2. UNAIDS (2011) World AIDS day report.

3. HAPCO F (2010) Report on Progress towards Implementation of the UN Declaration of Commitment on HIVIAIDS. AA: Federal ministry of health.

4. UNAIDS, WHO HIVIAIDS Programme (2007) Guidance on Provider-Initiated Testing and Counseling in Health Facilities. World Health Organization.
5. CDC (2004) US Centers for Disease Control and Prevention. Global AIDS Program: Strategies.

6. Managua, Nicaragua (2001) Organized by UNFPA with the Rockefeller Foundation, UNESCO and the Panos Institute, UNFPA, New York, USA.

7. Piotrow PT, Rimon JG, PayneMeritt A, Saffitz G (2003) Advancing Health Communication: The PCS Experience in the Field. Maryland, John hopkins Bloomberg School of Public Health, USA.

8. FHI (2002) Behavior Change Communication (BCC) for HIV/AIDS: A Strategic Framework. Institute for HIVIAIDS, Arlington, Virginia, Family Health International.

9. Witte K, Meyer G, Martell D (2001) Effective Health Risk messages a step-bystep Guide. Sage.

10. Witte K (1998) Fear as a motivator: using parallel process explain fear appea the extended model to successes and failures. In Andersen PA, Guerrero LK (eds.), Handbook of communication and emotion. Research, Theory, Applications and contexts. Academic Press, San Diego, USA, 425-450.

11. Witte K (1994) Generating effective risk messages. How scary should be your risk communication. Communication Yearbook 18: 229-254.

12. Witte K (1996) Fear control and danger control: An empirical test of the extended parallel process model. Communication Monographs 61: 113-134.

13. Witte K, Girma B, Girgre A (2001) Ethiopian reproductive health project. Family planning and HIVIAIDS prevention formative and base line study Addis Ababa: John Hopkins University/ population communication service and national office of population.

14. Getenet M, Tesfaye M, Ayele R, Gadisa T, Enqusillasie F, et al. (2005) HIV/ AIDS behavioral surveillance survey (BSS) Ethiopia. MOH/HAPCO.

15. Amsalu Sh (2004) Response to HIV prevention messages based on EPPM, among Bahr dar university students North West Ethiopia.

16. Hellen KM, Mukulu E (2011) Persuasive communication factors that influence University students in their responses to HIVIAIDS prevention campaign message. International Journal of Humanities and Social Science 1: 254-260.

17. FHI (2005) Iringa youth behavioral survey.

18. Alemu D (2010) Assessment of sexual risk perception and the determinants of protective behaviour of STIS/HIVIAIDS among female college students in debere-markos town, Amhara regional state, Ethiopia. AAU MPH Student unpublished thesis.

19. Gore TD, Bracken CC (2005) Testing the Theoretical Design of a Health Risk Message: Reexamining the Major Tenets of the Extended Parallel Process Model. Health Educ Behav 32: 27-41. 